\title{
The management of atrial fibrillation: summary of updated NICE guidance
}

\begin{abstract}
Addition-NICE has produced a Patient Decision Aid to be used alongside the guideline (BMJ 2014;348:g3655, doi:10. $1136 / \mathrm{bmj} . \mathrm{g} 3655)$. It is designed to help patients weigh up the possible benefits, harms, advantages, and disadvantages of the different options for treatment, so that they can better discuss them with a health professional and come to a decision together. The PDA includes a tool for patients to rate what is and isn't important to them in stroke prevention. It also has visual
\end{abstract}

representations of the risks and benefits of the treatments to prevent stroke.

The PDA is available on the NICE website at http://guidance. nice.org.uk/CG180

Cite this as: BMJ 2014;349:94440

๑ BMJ Publishing Group Ltd 2014 